Supplement of Biogeosciences, 17, 3409-3425, 2020 https://doi.org/10.5194/bg-17-3409-2020-supplement (C) Author(s) 2020. This work is distributed under the Creative Commons Attribution 4.0 License.

(c) (1)

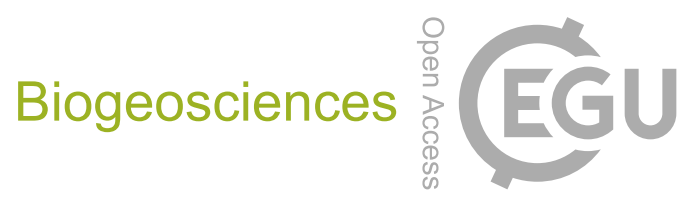

Supplement of

\title{
Carbon dioxide and methane fluxes from different surface types in a created urban wetland
}

\section{Xuefei Li et al.}

Correspondence to: Xuefei Li (xuefei.z.li@helsinki.fi)

The copyright of individual parts of the supplement might differ from the CC BY 4.0 License. 


\section{Alternative gap-filling method}

Besides the gap-filling method using artificial neural network (ANN) as described in the manuscript, we also gap-filled the missing net ecosystem exchange (NEE) measured by eddy covariance techniques without using the dissolved gas concentration in the water. We used the following parameterization based on biological principles (Aurela et al., 2009):

$$
N E E=\frac{P I \times \alpha \times P P F D \times G P_{\max }}{\alpha \times P P F D+G P_{\max }}+R_{0} \exp \left[E\left(\frac{1}{T_{0}}-\frac{1}{T_{a i r}+T_{1}}\right)\right],
$$

where NEE is the net ecosystem CO2 exchange, $G P_{\max }$ is the gross photosynthesis rate in optimal light conditions, PI is an empirically determined effective phytomass index (Aurela, Tuovinen et al. 2001), $\alpha$ is the initial slope of NEE versus PPFD, $R_{0}$ is the rate of ecosystem respiration at $10{ }^{\circ} \mathrm{C}, \mathrm{E}$ is a physiological parameter (in degree Kelvin), $\mathrm{T}_{\text {air }}$ is the air temperature, $\mathrm{T}_{0}=56.02 \mathrm{~K}, \mathrm{~T}_{1}=227.13 \mathrm{~K}$ (Lloyd and Taylor

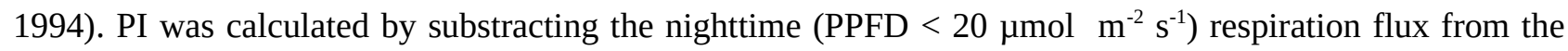
daytime (PPFD $>500 \mu \mathrm{mol} \mathrm{m}^{-2} \mathrm{~s}^{-1}$ ) flux. The PI was calculated on a six-day basis. During summer time ( day of year 90 - 283), E was determined by fitting the respiration to the nighttime data through the year, which was $342.24 \mathrm{~K} . \alpha, \mathrm{GP}_{\max }$ and $\mathrm{R}_{0}$ wre fitted in b-weekly periods: an $\mathrm{R} 0$ value was first determined by fitting the respiration to the nighttime data for each of these periods, then the values of $\alpha$ and $\mathrm{GP}_{\max }$ were obtained by fitting the NEE equations to the daytime and nighttime data. During winter when no uptake of CO2 was observed, the gaps were filled by a moving average with a 30-day window. At the beginning and end of the winter periods, the window was 8 days.

For gap-filling $\mathrm{CH}_{4}$ flux during year 2013, we explored the dependence of methane emission on air temperature and water temperature. Only days with data coverage better than $33 \%$ was used in this analysis, which resulted 94 daily averages based on measured data. As the behavior of the flux seems to be different before and after day of year (DOY) 160, two exponential curves were fitted separately to the data within these two periods. The fitting results can be described in the equation below

$\mathrm{F}=\mathrm{a} \exp [\mathrm{b} \mathrm{T}]$,

where $\mathrm{T}$ indicates air temperature or outflow water temperature. When fitted with air temperature, $\mathrm{a}=0.433$ $\mathrm{mg} \mathrm{m}{ }^{-2} \mathrm{~h}^{-1}, \mathrm{~b}=0.093{ }^{\circ} \mathrm{C}$ for data before DOY 160 and $\mathrm{a}=0.265 \mathrm{mg} \mathrm{m}^{-2} \mathrm{~h}^{-1}, \mathrm{~b}=0.057^{\circ} \mathrm{C}$ for data after day 160. The correlation coefficients were 0.95 and 0.72 , respectively. When fitted with outflow water temperature, $\mathrm{a}=0.362 \mathrm{mg} \mathrm{m}^{-2} \mathrm{~h}^{-1}, \mathrm{~b}=0.105^{\circ} \mathrm{C}$ for data before day 160 and $\mathrm{a}=0.181 \mathrm{mg} \mathrm{m}^{-2} \mathrm{~h}^{-1}, \mathrm{~b}=0.077^{\circ} \mathrm{C}$ for data after DOY 160 . The correlation coefficients were 0.94 and 0.78 , respectively. To maximize the goodness of fit, air temperature was used in gap-filling for data points before DOY 160 while outflow water temperature was used for after DOY 160. 


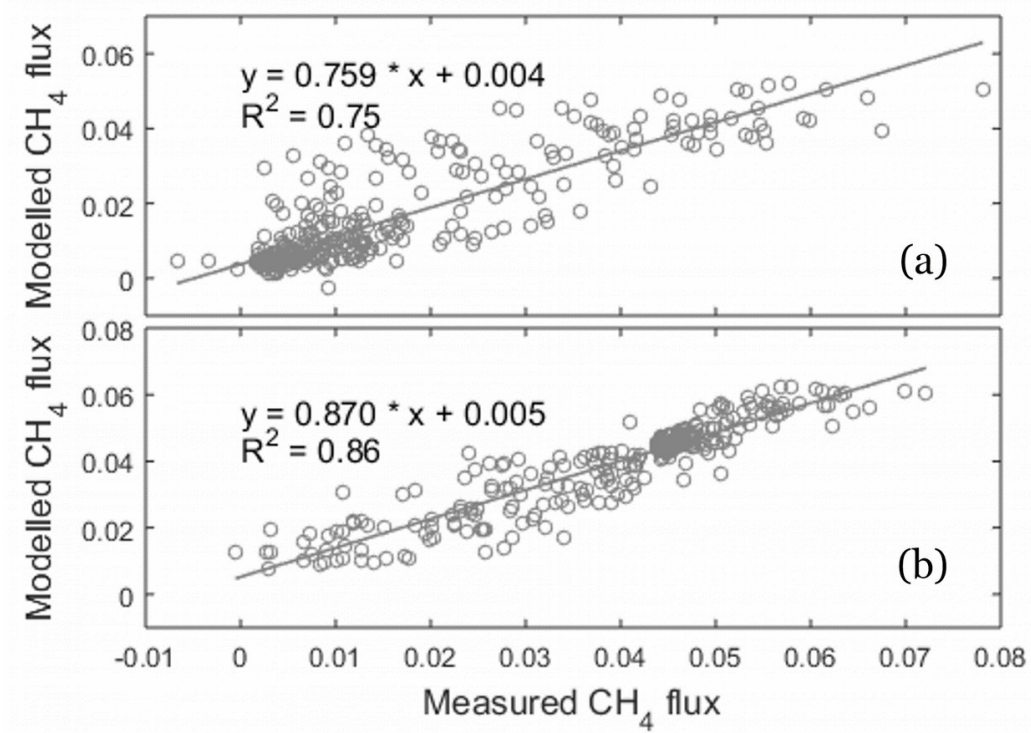

Figure S1: Comparing the modelled and measured ecosystem flux (using $\mathrm{CH}_{4}$ as example) (a) without or (b) with dissolved gas concentration in open water $\left(\left[\mathrm{CH}_{4}\right]\right.$ in this case) in artificial neural network architecture.

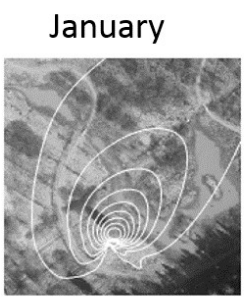

May

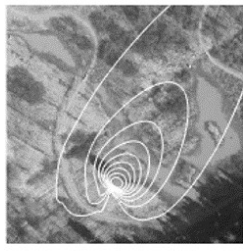

September

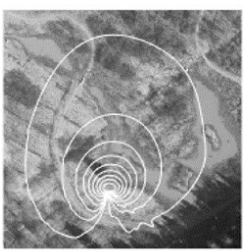

February

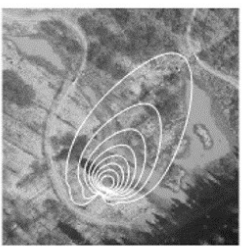

June

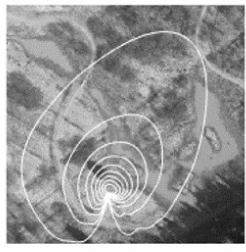

October

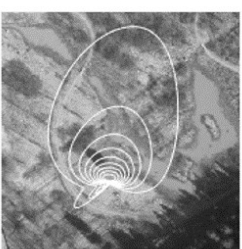

March

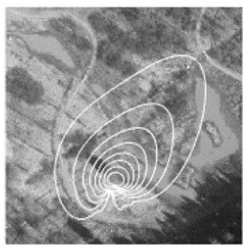

July

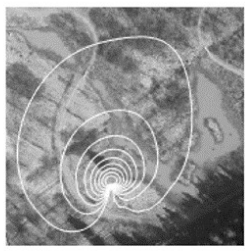

November

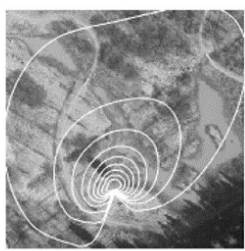

April

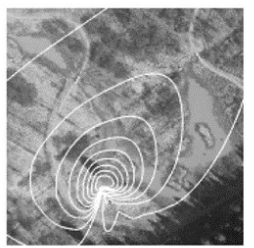

August

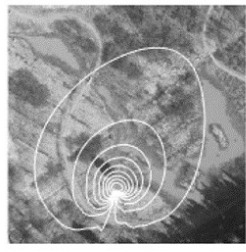

December

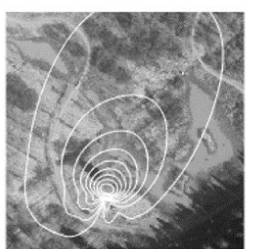

Figure S2: The aggregated footprint climatology of Nummela wetland during each month in year 2013. White contour lines show $10 \%$ - $90 \%$ flux footprint climatology. 


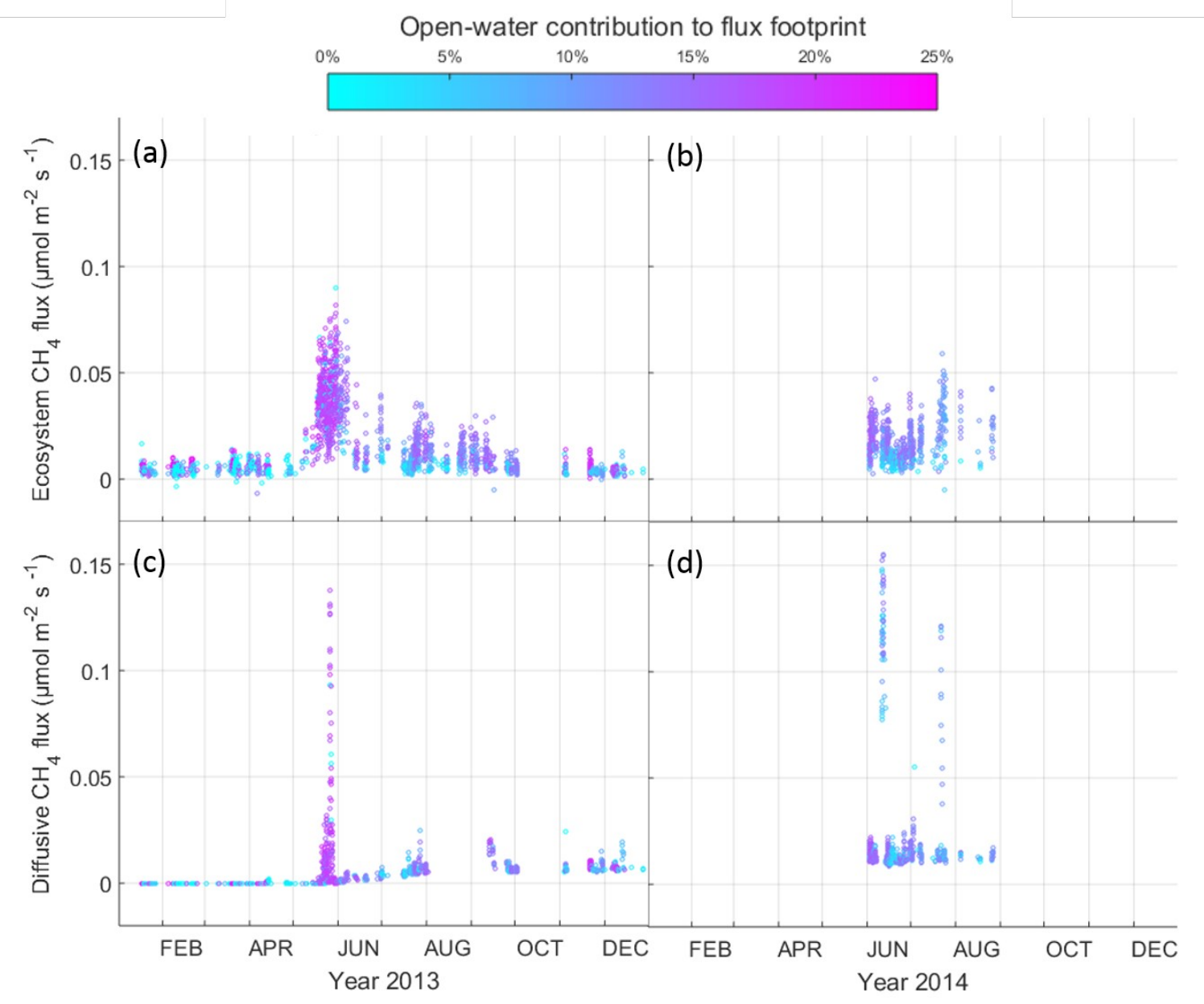

Figure S3: Ecosystem $\mathrm{CH}_{4}$ flux measured by eddy covariance tower ((a) and (b)) and diffusive $\mathrm{CH}_{4}$ flux modelled from open water ((c) and (d)). The colour bar indicates the footprint-weighted spatial contribution from the open water. 